\title{
Interface Design Heuristic Evaluation Website Yayasan Kesehatan Telkom
}

\author{
Alfira Febriyanthi', Muhammad Nadhif Naufal' ${ }^{1}$, Muhammad Rahmatullah', Islahuddin ${ }^{4}$, \\ Parlindungan, SE, MT, Ak. ${ }^{5}$
}

\author{
S1 Information Systems Study Program, Faculty of Engineering, Widyatama University, Indonesia \\ alfira.febriyanthi@widyatama.ac.id ${ }^{1}, \quad$ nadhif.naufal@widyatama.ac.id ${ }^{2}$, \\ muhammad.rahmatullah@widyatama.ac.id ${ }^{3}$, islahuddin@widyatama.ac.id ${ }^{4}$, parlindungan.mt@widyatama.ac.id ${ }^{5}$
}

Article History: Received:11 January 2021; Accepted: 27 February 2021; Published online: 5 April 2021

\begin{abstract}
The webpage portal is a means of information for companies to introduce company profiles, job vacancies, and their products to the public or its users. Heuristic evaluation (Nielsen 1990) is a method that researchers use to test the usability of a web page portal application. The Heuristic Evaluation Method uses ten Nielsen principles, namely Visibility of system status, match with the real world, user control and freedom, consistency and standard, error prevention, recognition than recall, flexibility and efficiency of use, aesthetic and minimalist design, help user recognize, diagnose, and recover from errors, and Help and documentation. The results of the analysis show that there are only 5 variables that have a significance of less than 0.05 . Of the independent variables,
\end{abstract}

Keywords: Telkom health foundation, heuristic evaluation, information system

\section{Introduction}

Currently, the development of information technology is growing rapidly, the need for software is also getting higher in various fields. Yakes Telkom is an online application (cloud) that can be accessed online using the internet network, this site is used as a forum for companies to provide all information about Telkom health foundations that can be accessed by all groups. It is important for companies to provide a platform that can be understood by all users, therefore it is necessary to have an approach to see the success of the site.

In a website, user satisfaction is a measure of success in other words, if the website that users access is easy, then it can be said that the website is successful and functioning properly. vice versa. There is an approach that can be used to measure user experience, namely the usability aspect approach. with this it can be used to see the success of the website from its use. With this, the appraiser of a product that can be used by certain users can be used to achieve certain goals and satisfaction in a particular usage context in an effective, efficient manner.

In the usability aspect, there are 3 main aspects used to measure the success of a website, namely the first, effectiveness can be seen to what extent the user's success in running the website, the second is user efficiency and accuracy in running website applications and the third or last is satisfaction and user convenience in accessing the website.

Bearing in mind that website users come from all walks of life, it is necessary to do usability testing which can be used to see and assess the success of the website. Because a good website can increase the interaction between users and the existing system, and can make users come back to visit the website again. Likewise, a bad website will make users bored and uninterested and dissatisfied when visiting a website. However, to meet this need, there must be a method used to find usability problems, the method used is heuristic evaluation. With the heuristic evaluation, it is expected to be able to increase the success of the website in understanding the user experience.

This research plays a role in the development of the health foundation's website Telkom itself, because there are very few articles that discuss the functionality and how this Telkom health foundation site acts as a website that provides information about Telkom health foundations which are supported by complete features in it to help its users. Through the heuristic evaluation research on the website of the Telkom Health Foundation, it is hoped that it can provide an accurate assessment of the appropriateness and reliability of a website with a severity rating scale of $0-4$. 


\section{Literature Review}

\section{Discussion of Relevant Research Results}

To be able to obtain a hypothesis that is considered correct, several previous studies are listed which can serve as comparisons and references and views that are considered accurate regarding the research taken.

a. The results of research by Dede Atmaja et al.

Title: Heuristic Evaluation of E-Money Application Interface Design Case Study in Banyuasin Regency

Authors: Dede Atmaja et al.

According to Dede et al., this research is focused on the use of heuristic evaluation based on user interface design aspects of application usability through interviews, questionnaires and observations to users as well as literature studies that enable problems solving and making decisions quickly and efficiently. Application testing with heuristic evaluation in this study uses ten Nielsen principles, namely visibility of system status, match with the real world, user control and freedom, consistency and standard, error prevention, recognition than recall, flexibility and efficiency of use, aesthetic and minimalist designs, help users recognize, diagnose, and recover from errors, and Help and documentation.

b. The results of research by Amir Ali et al.

Title: Heuristic Evaluation in Web Based Learning to Improve System Usability Aspects.

Authors: Amir Ali et al.

According to Amir Ali et al., this type of research uses descriptive research methods. The interface page will be evaluated using the heuristic evaluation method which uses 10 principles of heuristic rules proposed by Jacob Nielsen and Mack. Then carried out usability testing [6] and the calculation of the scale of satisfaction and ease of use of applications with a Likert scale, as well as conducting a reliability test using Cronbach alpha. Calculation [2].

c. The results of research by Tengku Khairil Ahsyar et al.

Title: Usability Evaluation of SIAM Academic Information System Using Heuristic Evaluation Method Authors: Tengku Khairil Ahsyar et al.

According to Tengku Khairil Ahsyar et al., this study uses Heuristic Evaluation as an inference method to assess the components of learnability, efficiency, memorability, errors, and satisfaction [10]. Distribution of questionnaires using random sampling techniques, is the distribution of all members of the population randomly regardless of the existing strata in the population [9]. The questionnaire in this study was designed based on 10 principles, namely visibility of system status, match between system and real world, user control and freedom, consistency and standard, error prevention, recognition rather than recall, flexibility and efficiency of use, aesthetic and minimalist design, help. user recognize and recover from errors, and help and document [8] to determine system quality based on the ease and comfort of system users. Validity and reliability testing is carried out to determine whether all statements submitted in measuring the variables are valid. This study uses a Likert 4 rating scale, with a measurement of the level of agreement Strongly Agree, Agree, Disagree, and Strongly Disagree [3].

\section{Methodology}

\subsection{Research methodology}

The research method used is descriptive analytical method with a quantitative approach, namely research using observations, interviews or questionnaires regarding the current situation, regarding the subject we are studying. Through questionnaires and so on, we collect data to test hypotheses or answer a question [4].

\subsection{Heuristic evaluation}

Heuristic Evaluation is an informal method that is carried out by examining an application or software. The approach coined by Nielsen and Molich in 1990 is to look at the interface and try to make an opinion about what is good and bad about the interface. Ideally one would conduct such an evaluation for certain rules, as listed in the document's general guidelines [5].

Nielsen and Molich developed 10 heuristic usability principles for interface design, as follows [6]:

1. Visibility of system status,

2. Match between the system and the real world, 
3. User Control and Freedom,

4. Consistency and standard,

5. Error prevention,

6. Recognition rather than recall,

7. Flexibility and efficiency of use,

8. Aesthetic and minimalist design,

9. Help user recognize, diagnose and recover from errors,

10. Help and documentation.

\subsection{Usability}

Usability is a quality attribute that measures how easy the user interface is to use. Usability also refers to methods to increase ease of use during the design process [7]. There are 5 components of usability, as follows:

1. Learnability

Learnability describes how easy it is for users to complete basic tasks the first time they encounter the app.

2. Efficiency

Efficiency describes how quickly they complete a task after they have studied the application.

3. Memorability

Memorability describes how much users remember the information system after a period of not using it and how easily they can rebuild their skills.

4. Errors

Errors describes how many errors the user has made. How many errors and how much ease is it to fix the errors.

5. Satisfaction

Satisfaction explain the level of satisfaction in using the application.

\subsection{Website}

Website or website is the entire web page contained in a domain that contains information. A website is generally built on interconnected web pages. The relationship between one web page and another web page is called a hyperlink, while the text that is used as a connecting medium is called hypertext [8].

Domain is a unique name that is owned by an institution so that it can be accessed via the internet, for example muhammadrahmatullah.com, yakestelkom.com, google.com, and others [9]: to get a domain, you can register the domain in the specified registers.

Types of websites and by their nature are:

1. Dynamic websites are websites that provide content or content that changes from time to time. For example, news websites, such as www.kompas.com, www.detik.com, polinpdg.ac.id, and others.

2. Static web sites are websites whose content is rarely changed, for example, the web profile of an organization and others [9].

The process and stages in this research started from literature study and data collection and analysis to the preparation of the final report. The procedures and stages of this research can be seen in Figure 1: 


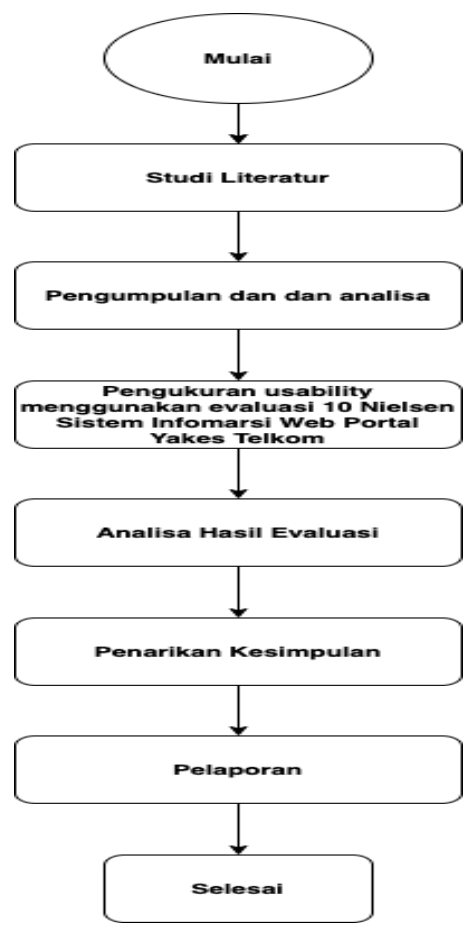

Figure 1. Research flow

Starting with a literature study to obtain the required data and references, followed by data collection and analysis to provide an overview of the assessment and selection of the method used. Furthermore, the measurement of the Yakes Telkom website uses the Nielsen ten heuristic evaluation method by distributing questionnaires, then calculating and recapitulating the average test score results on the Telkom health foundation website and ending with drawing conclusions.

Based on the analysis of advantages and disadvantages conducted by Nielsen, the recommended number of examiners in the heuristic evaluation process is three to five people. Basically, heuristic evaluation is not easy to do, because it is very difficult for individuals to be able to find all usability problems in an interface design. However, heuristic evaluation has been widely used because the process can be carried out in a short period of time and with limited funds [10].

The method used in this study is divided into two, namely distributing questionnaires to the research object being tested and calculating the results of the heuristic evaluation of the Telkom health foundation site. The questionnaire was conducted on 2 respondents consisting of staff from the Telkom Health Foundation application development division. The contents of the questionnaire were developed from existing heuristic evaluation methods. Development is related to the Usability dimension and question attributes on the questionnaire. The selection of dimensions and attributes is based on the results of previous literature studies, in order to obtain a questionnaire design that aims to capture problems and assess usability more accurately. Usability aspects and the development of usability sub-aspects are as listed in Table 1.

Table 1. Heuristic evaluation aspects table

\begin{tabular}{clc}
\hline No. & Usability Aspects & Code \\
\hline 1 & Match Between System and the Real World & $\mathrm{H} 1$ \\
\hline 2 & User Control and Freedom & $\mathrm{H} 2$ \\
\hline 3 & Consistency and standards & $\mathrm{H} 3$ \\
\hline 4 & Error prevention & $\mathrm{H} 4$ \\
\hline 5 & Recognition rather than recall & $\mathrm{H} 5$ \\
\hline 6 & Flexibility and efficiency of use & $\mathrm{H} 6$ \\
\hline 7 & Aesthetic and minimalist design & $\mathrm{H} 7$ \\
\hline 8 & Help users recognize, diagnose, and recover H9 from errors & $\mathrm{H} 8$ \\
\hline 9 & Help and documentation & $\mathrm{H} 9$ \\
\hline 10 & Visibility of system status & $\mathrm{H} 10$ \\
\hline
\end{tabular}




\subsection{Data analysis method}

The calculation of the results of the questionnaire was obtained through the mean of each attribute in each dimension / principle of usability developed. The heuristic evaluation value is obtained by performing calculations based on Table 1. Each usability aspect in the heuristic evaluation has a usability sub-aspect which is a development point in accordance with the usability aspect. The calculation for the heuristic evaluation uses equation (1):

$\sum \mathrm{Hx}=(0 * \mathrm{x})+(1 * \mathrm{x})+(2 * \mathrm{x})+(3 * \mathrm{x})+(4 * \mathrm{x})$

With,

$\sum \mathrm{Hx}=$ total rating score from the usability sub-aspect in each aspect usability $(\mathrm{H} 1, \mathrm{H} 2$,

Furthermore, to produce a severity rating from each usability aspect using equation (2):

$\mathrm{Sv}=\sum \mathrm{Hxn} n$

With,

$\mathrm{Sv}=$ the result of the severity rating in one aspect of usability

$\mathrm{n}=$ the number of usability sub-aspects in each usability aspect [10].

Table 2. Severity rating scale

\begin{tabular}{cl}
\hline Severity Rating & \multicolumn{1}{c}{ Information } \\
\hline 0 & There were no problems or deficiencies in usability found. \\
\hline 1 & $\begin{array}{l}\text { For cosmetic problem category, the problem does not need to be fixed unless the project time } \\
\text { is still available. }\end{array}$ \\
\hline 2 & Minor usability problem category, minor usability problem, this fix is given a low priority. \\
\hline 3 & $\begin{array}{l}\text { Major usability problem category, main usability problem, important improvement is made, } \\
\text { therefore it is given high priority. }\end{array}$ \\
\hline 4 & $\begin{array}{l}\text { Catastrophe usability category, this problem of repair must be done before the product is } \\
\text { launched. }\end{array}$ \\
\hline
\end{tabular}

\section{Results and Discussion}

The appearance of the Telkom health foundation website that will be evaluated is in Figure 2-4.

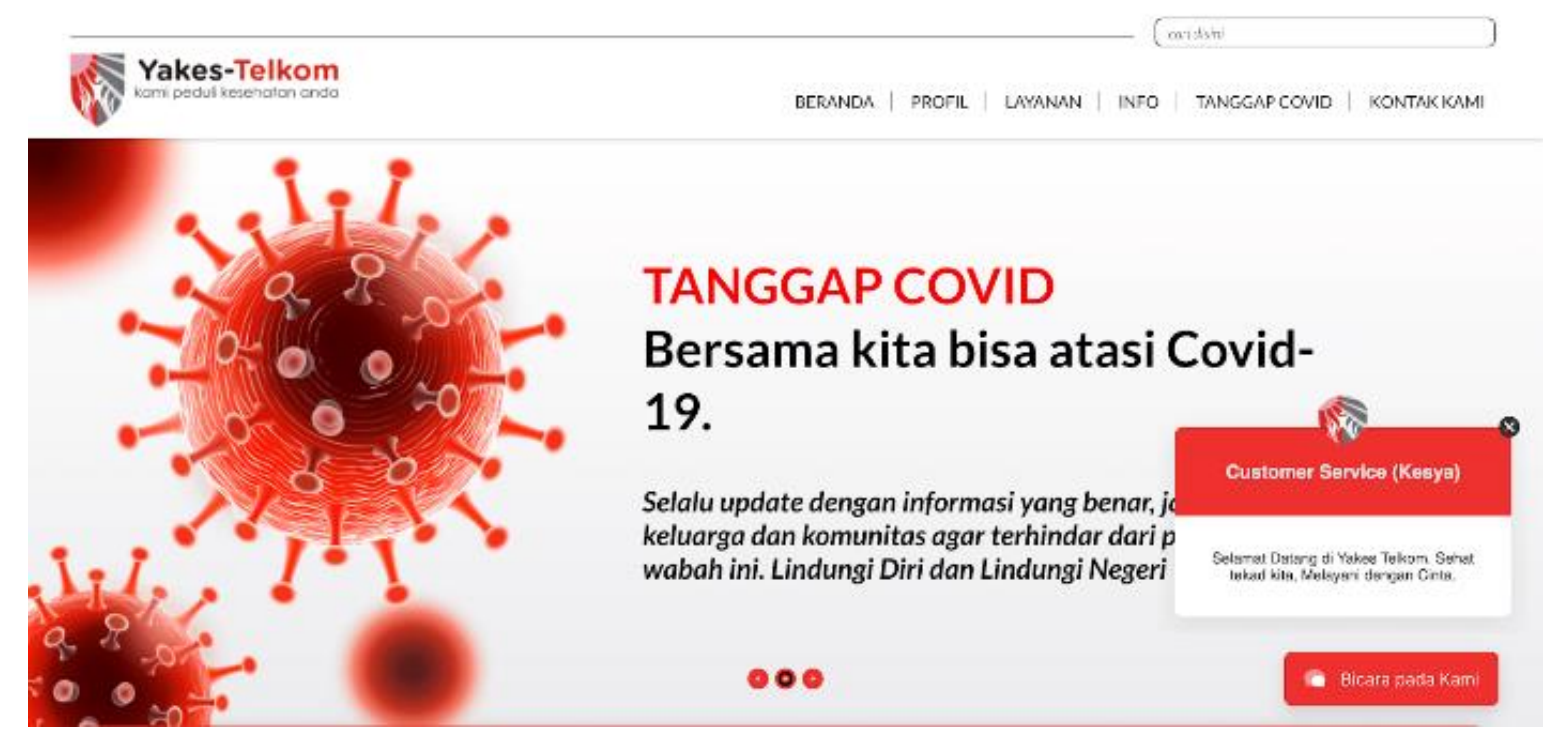

Figure 2. Screenshot of the home page of the Telkom health foundation website 
Alfira Febriyanthi ${ }^{1}$, Muhammad Nadhif Naufal ${ }^{2}$, Muhammad Rahmatullah $^{3}$, Islahuddin ${ }^{4}$, Parlindungan, SE, MT, Ak. ${ }^{5}$

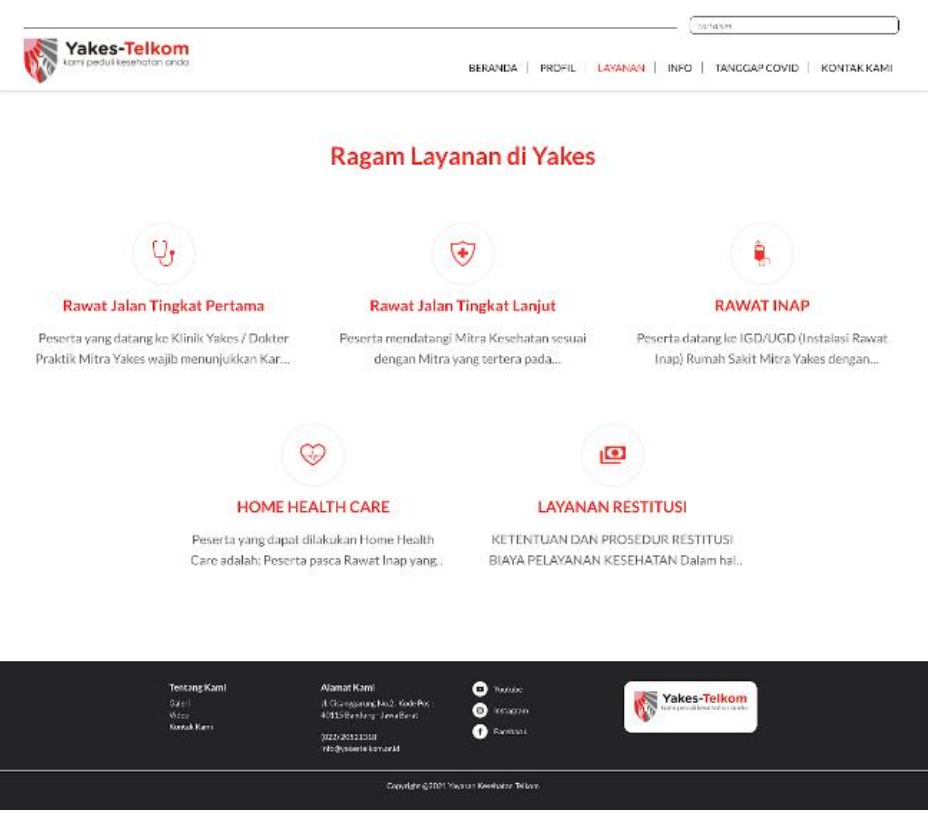

Figure 3. Screenshot of Telkom's health foundation website services page

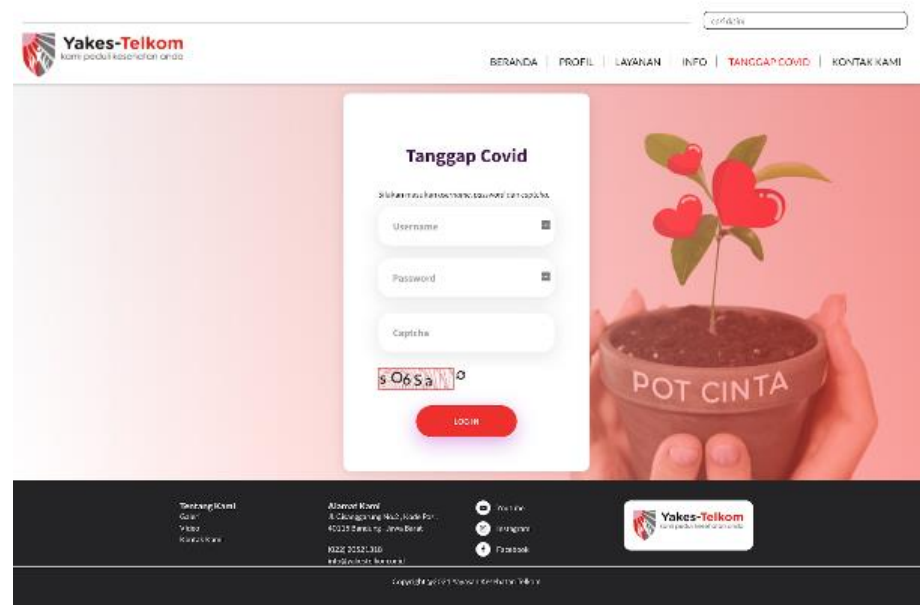

Figure 4. Screenshot of the COVID response page on the Telkom health foundation website

Table 3. Usability aspects and sub-aspects used

\begin{tabular}{ccl}
\hline No. & Usability Aspects & \multicolumn{1}{c}{ Usability Sub Aspects } \\
\hline 1 & $\begin{array}{c}\text { Match Between System and the } \\
\text { Real World }\end{array}$ & $\begin{array}{l}\text { 1. Icons, symbols, or thumbnails on web site pages are usable and } \\
\text { easy to understand. } \\
\text { 2. Language choices for users on the Telkom health foundation } \\
\text { web page. }\end{array}$ \\
\hline 2 & User Control and Freedom & $\begin{array}{l}\text { 1. Help button on the Telkom health foundation website. } \\
\text { 2. Search field options on the Telkom health foundation website. }\end{array}$ \\
\hline 3 & Consistency and standards & $\begin{array}{l}\text { 1. All pages already have a title. } \\
\text { 2. The information section on each page of the website is } \\
\text { consistent for its writing. }\end{array}$ \\
\hline 5 & Error prevention & $\begin{array}{l}\text { 1. Notification or pop up if there is an input error. } \\
\text { 2. The instructions contained in the navigation are clear and not } \\
\text { confusing. }\end{array}$ \\
\hline 6 & Flexibility and efficiency of use & $\begin{array}{l}\text { 1. Technical error message when failed to access the page (e.g. } \\
\text { Display source code). } \\
\text { 2. An error message if the user fills in the wrong form (for } \\
\text { example, a maximum phone number of 12 digits). }\end{array}$ \\
\hline
\end{tabular}




\begin{tabular}{|c|c|c|}
\hline & & $\begin{array}{l}\text { 2. The information displayed on each menu is appropriate and } \\
\text { sufficiently includes information for the user. }\end{array}$ \\
\hline 7 & Aesthetic and minimalist design & $\begin{array}{l}\text { 1. The information display or navigation menu is easy for novice } \\
\text { users to understand. } \\
\text { 2. The menu layout is familiar and users can easily access it. } \\
\text { 3. Different colors of the navigation keys (for example, the save } \\
\text { button is blue and the delete button is red) }\end{array}$ \\
\hline 8 & $\begin{array}{l}\text { Help users recognize, diagnose, } \\
\text { and recover H9 from errors }\end{array}$ & $\begin{array}{l}\text { 1. The information displayed on each page allows the user to } \\
\text { make a decision. } \\
\text { 2. The structure of each page is consistent and uniform. } \\
\text { 3. The title of each page is clear and informative. }\end{array}$ \\
\hline 9 & Help and documentation & $\begin{array}{l}\text { 1. Menu help that can help users. } \\
\text { 2. Contact the help center so that users can contact the site } \\
\text { administrator if they experience problems. }\end{array}$ \\
\hline 10 & Visibility of system status & $\begin{array}{l}\text { 1. Each page has a title describing the content on the web portal. } \\
\text { 2. Every symbol or icon and the design on every page is always } \\
\text { consistent. } \\
\text { 3. Visually different responses when pressing or selecting a } \\
\text { button. } \\
\text { 4. The menu and page titles match the contents. } \\
\text { 5. Each menu or page display can show the difference. }\end{array}$ \\
\hline
\end{tabular}

Based on the results of the questionnaire it was stated that, 10 aspects of the heuristic evaluation method by Nielsen have a severity rating of 1 (one), which means that errors or deficiencies can be tolerated by users [10]. In other words, the usability problem contained on the Telkom health foundation website is not a problem by site users and is deemed not to disturb users when accessing the Telkom health foundation website. The highest severity rating is in the User Control and Freedom aspect with a severity rating of 1.072580645. For the complete heuristic evaluation questionnaire data processing results on the Telkom health foundation website can be seen in Table 4.

Table 4. Recapitulation of severity rating values on Telkom health foundation website

\begin{tabular}{cccc}
\hline No. & Usability Aspects & Average Value of Severity Rating & Value Rounding Scale 0-4 \\
\hline 1 & $\begin{array}{c}\text { Match Between System and The } \\
\text { Real World }\end{array}$ & 0.8629032258 & 1 \\
\hline 2 & User Control and Freedom & 1.072580645 & 1 \\
\hline 3 & Consistency and standards & 0.9193548387 & 1 \\
\hline 4 & Error prevention & 1 & 1 \\
\hline 5 & Recognition rather than recall & 1.008064516 & 1 \\
\hline 6 & Flexibility and efficiency of use & 0.9677419355 & 1 \\
\hline 7 & Aesthetic and minimalist design & 0.9139784946 & 1 \\
\hline 8 & Help users recognize, diagnose, and & 0.8817204301 & 1 \\
\hline 9 & recover H9 from errors & & 1 \\
\hline 10 & Help and documentation & 0.8629032259 & 1 \\
\hline
\end{tabular}

\section{Conclusion}

Based on the results of the data processing that has been done before, it can be concluded in this study are as follows:

1. The results of the test, there are several aspects whose value is below what it should be, but these aspects are not very important aspects. So that these problems can still be tolerated by users and do not interfere with user comfort when accessing the Telkom health foundation website.

2. From the test value, it produces a severity rating of 0.94 , which means that the problem does not have to be fixed directly, but can be fixed when there is development.

3. The usability level of the information system on the Telkom health foundation website uses the heuristic evaluation method, which is included in the efficient testing category, because the questionnaire design aims to address problems and assess usability. more accurate. 


\section{References}

[1] MD Atmaja, Megawaty, and S. Sauda, (2014), "Heuristic Evaluation of E-Money Application Interface Design Case Study in Banyuasin District".

[2] A. Ali, Edwin P, and S. Tjandra, (2016), "Heuristic Evaluation on Web Based Learning to Improve System Usability Aspects".

[3] Ahsyar, T. K. (2019). Evaluasi Usability Sistem Informasi Akademik SIAM Menggunakan Metode Heuristic Evaluation. Seminar Nasional Teknologi Informasi Komunikasi dan Industri, pp. 163-170.

[4] Russeffendi, ET (2010), Basics of Educational Research and Other Non-exact Fields. Bandung: Tarsito.

[5] Nielsen, J., \& Molich, R. (1990). Heuristic evaluation of user interfaces. SIGCHI Conference on Human Factors in Computing Systems, pp. 249-256.

[6] J. Nielsen, “10 Usability Heuristics for User Interface Design,” Conference Companion on Human Factors in Computing Systems, 1994.

[7] J. Nielsen, 2012. https://www.nngroup.com/articles/usability-101-introduction-to-usability/.

[8] Yuhefizar, Ir. HA Mooduto, and R. Hidayat, (2005), "Interactive Website Using Joomla. PT. Elex Media Komputindo Gramedia Group".

[9] E. Sinduningrum, et al, (2018), "Implementation of CMS in Learning Media to Get to Know Indonesian Traditional Musical Instruments". Journal of Multinetics, Vol. 4, No. 2.

[10] LD Farida, (2016), "Measuring User Experience Using a Usability Approach (Case Study: Tourism Websites in Southeast Asia)". SEMNASTEKNOMEDIA.

[11] RFA Aziza, YT Hidayat, (2019), "Usability Analysis of User Interface Design on the Tokopedia Website Using the Heuristics Evaluation Method". Teknokompak Journal, Vol. 13, No. 1. 